ARCHIVOS

de historia del movimiento obrero y la izquierda
ISSN 2313-9749

ISSN en línea 2683-9601

Año VIII, $\mathrm{n}^{\circ} 16$, pp. 155-175

marzo de 2020-agosto de 2020

\title{
Críticos y solidarios. El anarquismo argentino ante la Guerra Civil Española
}

\author{
Jacinto Cerdá
}

Universidad de Buenos Aires - Universidad de San Andrés - Instituto Superior de Profesorado Joaquín V. González (Buenos Aires, Argentina) • jacinto_cerda@yahoo.com.ar

Tittle: Critical and Supportive. Argentine anarchism and the Spanish Civil War

Resumen: El presente trabajo explora las repercusiones que produjo la Guerra Civil española en el movimiento anarquista argentino, exponiendo las acciones solidarias desplegadas, los vínculos asociativos entablados, la trayectoria de los voluntarios que viajaron a participar directamente del conflicto armado y los debates políticos originados como reacción al rumbo fijado por las organizaciones libertarias de España. Nos abocaremos a analizar lo actuado por las entidades más representativas del campo libertario de Buenos Aires: Federación Anarco Comunista Argentina, Alianza Obrera Spartacus, periódico La Protesta y Federación Obrera Regional Argentina, de forma de proporcionar una mirada integral de lo realizado por los anarquistas locales.

Palabras clave: anarquismo - Guerra Civil española - solidaridad - voluntarios

\begin{abstract}
The present work explore the repercussions that produced the Spanish Civil War in the argentine anarchism movement, exposing the solidarity actions deployed, the associative links established, the trajectory of the volunteers who traveled to participate directly in the armed conflict, and the political debates originated as a reaction to the course set by the libertarian organizations of Spain. We will focus on analyzing the actions taken by the most representative entities of the libertarian camp of Buenos Aires: Federación Anarco Comunista Argentina, Alianza Obrera Spartacus, newspepar La Protesta and Federación Obrera Regional Argentina, of worse to provide an integral view of what has been done by local anarchist.
\end{abstract}

Keywords: anarchism - spanish civil war - solidarity - voluntaries

Recepción: 30 de junio de 2019. Aceptación: 13 de febrero de 2020 


\section{Introducción}

La guerra desatada en el interior de España a partir de julio de 1936, producto de la sublevación militar dirigida al gobierno del Frente Popular, acarreó grandes repercusiones a nivel internacional, manifestando algo más que el enfrentamiento de dos bandos políticos regionales. Por el contrario, el estallido de la Guerra Civil española (de aquí en más GCE) reveló de forma explícita la disputa que se estaba desarrollando en numerosas partes del planeta ante el auge de los regimenes autoritarios y la impugnación del liberalismo.

El gobierno que asumió el poder durante la II República Española en febrero de 1936 era una coalición de partidos de izquierda encabezada por los republicanos de Azaña, cuyo programa planteaba una serie de reformas progresistas, pero no revolucionarias, como temían sus opositores de derecha. Ante el recrudecimiento de la violencia política durante los primeros meses de gobierno se produjo el alzamiento militar del 18 de julio, y con este el inicio de la guerra. La colaboración externa hacia el sector de los sublevados fue inmediata, contando con acuerdos previos al golpe de parte de las potencias del Eje. En cambio el gobierno constitucional no recibió el mismo trato por parte de sus pares democráticos, como podría haberse esperado de Gran Bretaña y especialmente de Francia, donde también gobernaba una coalición socialdemócrata. Estas potencias aplicaron la política de "no intervención" bajo el argumento de evitar que el conflicto cobre dimensiones internacionales; preocupados por la incapacidad del gobierno para neutralizar el accionar de los sectores "extremistas", temían por la influencia que los comunistas podrian obtener bajo esas circunstancias. Efectivamente, el único apoyo estatal que recibió la República, aunque limitado y retaceado, fue de parte de la URSS. Paralelamente, voluntarios de todos los rincones del mundo se incorporaron como combatientes de las Brigadas Internacionales para evitar el avance del proyecto fascista en la península ibérica (Jorge, 2014, pp. 165-179).

En Argentina, la preocupación que produjo la guerra se manifestó con gran intensidad, canalizándose a través de la movilización política y las campañas solidarias. Los bandos que se enfrentaron en los campos de batalla en España contaron con sus correligionarios en el plano local, y si bien existieron antecedentes que permitieron identificar a estos sectores dentro de la sociedad argentina, aquella demarcación no se cristalizó de forma fehaciente hasta la irrupción del conflicto español, dado que las diferencias políticas locales solian entablarse en torno a otras variables.

El movimiento anarquista de Argentina se vio fuertemente interpelado por los sucesos ibéricos, en tanto que los lazos entablados durante las 
décadas anteriores entre los libertarios de ambas regiones impulsaron a que los locales se involucren denodadamente con la "causa española". El propósito de este trabajo es indagar cómo se involucró esta tendencia en la campaña solidaria, tanto en sus aporte materiales como en el desarrollo de alianzas, detectar el perfil y las contribuciones de los voluntarios que participaron de la guerra, examinar de qué forma procesaron las noticias respecto a las políticas asumidas por sus camaradas de España y qué debates provocaron las mismas al interior del movimiento local. A través de estos ejes nos proponemos profundizar el conocimiento del heterogéneo ambiente anarquista durante la segunda mitad de la década del 30.

La GCE, además de darles mayor visibilidad a los anarquistas locales por su compromiso con la propaganda y recolección de donativos, puso de relieve las diferencias plasmadas en su interior. Es sabido que este movimiento sufrió grandes transformaciones a partir de la irrupción del golpe de Estado de septiembre de 1930. Las organizaciones revolucionarias -ácratas y comunistas- se vieron obligadas a actuar en la clandestinidad, mientras que cientos de sus militantes fueron encarcelados y deportados, otros tantos fueron fusilados (Penina, Di Giovanni, Scarfó y Morán, entre los más conocidos). Con el inicio del gobierno de Justo los sindicatos de la FORA retomaron su actividad pública, pero rápidamente fue cercenada con la reinstalación del estado de sitio en diciembre de 1932. Esa organización permaneció en el tiempo, concentrando sus efectivos en Buenos Aires, Capital Federal, Santa Fe y Tucumán, pero su radio de acción fue cada vez más reducido en detrimento del crecimiento de los sindicatos de la CGT.

Ante este complicado panorama, un sector del activismo ácrata tomó la iniciativa de reagrupar a los militantes de aquella tendencia a partir de crear grupos exclusivamente de anarquistas, la denominada corriente "especifista". De la unión de diversas agrupaciones del país se fundó la Federación Anarco Comunista Argentina (FACA) en 1935, proceso organizativo iniciado con el congreso efectuado dentro de la cárcel de Villa Devoto en 1931 y formalizado con la creación del Comité Regional de Relaciones Anarquistas (CRRA) en septiembre del año siguiente en la ciudad de Rosario. El especifismo proyectó su militancia dentro de los ámbitos estudiantiles, feministas, culturales y sindicales. Su táctica gremial fue, en un primer momento, insertarse dentro de la FORA para forzar su orientación hacia la organización por industria (en oposición a la tradicional estructuración por oficio), pero al comprobar que esto no era posible se volcaron a incidir en los gremios autónomos (López Trujillo, 2005, pp. 209-210).

En la misma década también se creó la Alianza Obrera Spartacus (AOS), agrupación surgida del equipo editorial del periódico La Antor- 
cha. Participó del CRRA pero luego no se sumó a la conformación de la FACA. Se presentaba como una organización de orientación sindical y campesina, impulsada por una política de apertura a la coordinación con otras corrientes "clasistas", en especial con los comunistas (Benyo, 2005, pp. 89-92). Al mismo tiempo siguieron existiendo una variedad de entidades culturales y artísticas, como bibliotecas y periódicos, entre los que se destacaron La Protesta, La Obra y La Batalla, que conformaron grupos de opinión más próximos a una organización u otra, pero orgánicamente independientes. Estas diferencias político-organizativas derivarán en distintas tácticas de inserción en la campaña a favor del pueblo español, en las cuales ahondaremos a continuación.

\section{La organización de la solidaridad}

El apoyo a los contendientes españoles se manifestó velozmente en Argentina, el júbilo o la angustia de la primera hora se expresó a través de múltiples cartas remitidas a la embajada de España. A su vez, la entidad diplomática recibió gran cantidad de solicitudes que pedían facilidades para trasladarse a la región en conflicto, con miras a ser incorporados al ejército leal. Estas peticiones no cobraron frutos, ya que la embajada, cumpliendo con lo dispuesto por las autoridades republicanas, rechazó cordialmente los ofrecimientos de colaboración militar de habitantes de otros países, basándose en la seguridad de que las fuerzas leales eran suficientes para abatir a los militares sublevados, ya que contaban con el apoyo del pueblo (Montenegro, 2002, p. 31). De esta forma el entusiasmo solidario pasó a estar encauzado, mayoritariamente, a través de recaudaciones, ya fuesen de ropa, dinero, viveres u otros objetos útiles para la población en guerra.

En una primera instancia esta actividad solidaria estuvo organizada por la esposa del embajador español, Teresa Diez Canedo, quien coordinó los donativos recibidos por la institución diplomática y los centros de la comunidad española más cercanos políticamente. La voluntad de contribuir con esta causa se volvió masiva y rápidamente sobrepasó la capacidad organizativa de estas entidades, derivando en la creación de múltiples centros de ayuda por todo el país. Fenómeno de autoorganización que rebasó con creces a la propia colectividad española residente en este país, de por sí muy numerosa.

Si bien estas iniciativas de asociación, más o menos inorgánicas y dispersas, se dedicaron principalmente a la organización de colectas, festivales, conferencias o publicación de materiales, progresivamente fueron decantando a favor de un sector específico de las fuerzas de izquierda actuantes, dependiendo de la preferencia ideológica y de la relación entablada con las organizaciones políticas preexistentes en el 
país. Mónica Quijada señala que los objetivos perseguidos por las diferentes tendencias políticas participantes de las campañas fueron dos: dotar de una mayor eficacia y coherencia a la ayuda destinada al pueblo español, y centralizar el movimiento de solidaridad, "bien con fines políticos, bien para sustraer a aquél del alcance de esta última influencia" (Quijada, 1991, p. 152). Esta última aclaración realizada por la autora alude, justamente, a la influencia ejercida por el sector anarquista en la campaña, quienes confrontaron con el Partido Socialista y el Partido Comunista por la dirección del movimiento solidario.

Siguiendo este planteo, el movimiento de ayuda al pueblo español se dividió en tres grandes agrupamientos determinados por su orientación politica: socialista, comunista o anarquista. Los primeros actuaron de forma coordinada con la embajada, que si bien como institución diplomática intentó no herir susceptibilidades, agradeciéndoles a todos y cada uno de los múltiples comités creados al calor de los acontecimientos, le otorgó un trato preferencial a la agrupación Amigos de la República Española (ARE), sección creada en julio de 1936 por el Centro Republicano Español (CRE) de Buenos Aires. De esta forma, la entidad trabajó codo a codo con la representación diplomática y el Partido Socialista, remitiendo sus donaciones directamente al gobierno republicano.

Los comunistas centralizaron su actividad por medio de la Federación de Organismos de Ayuda a la República Española (FOARE), entidad que agrupó muchos comités solidarios del país, los cuales en búsqueda de una mayor coordinación abandonaron su carácter autónomo. La táctica de "frente popular" respondió al cambio dictaminado por la Internacional Comunista de entablar la lucha antifascista por sobre la perspectiva de lucha frontal de "clase contra clase". En España esa política se implementó a través del lema "primero ganar la guerra", dejando la construcción revolucionaria para después de logrado ese objetivo. La FOARE alcanzó una coordinación a nivel nacional y declaró contar con 800 entidades adheridas, derivando en que se presente recurrentemente como la "verdadera" o la "única" organización que asistía al pueblo español (Montenegro, 2002, pp. 78-79). Lo recaudado por sus campañas no era remitido a través de la embajada, sino por medio del "Comité Internacional de Coordinación e Información Pro Ayuda a la República Española", con sede en París (Casas, 2007, pp. 41-45).

En el caso de los anarquistas, la manera de encauzar la ayuda hacia la población española manifestó serias discrepancias en su interior, ampliando sus diferencias políticas previas, al igual que sucedió en otras experiencias como en la huelga en contra de la ley de jubilaciones de 1924 entre foristas y antorchistas (Anapios, 2013, pp. 27-43). Las opciones en disputa para el caso aquí tratado se dirimieron entre expandir el área de influencia del propio movimiento libertario por medio de fomentar 
y apuntalar la formación de las nuevas organizaciones surgidas para la ocasión o, por el contrario, encauzar la campaña solidaria a través de las organizaciones preexistentes y coordinar esfuerzos con aquellas entidades de mayor vínculo ideológico.

En respaldo a la primera posición se ubicaron los integrantes de la FACA y de la AOS, quienes, además de acompañar la creación de los espontáneos Comités de Apoyo al Proletariado Español (CAPE), rápidamente entablaron contactos con otras entidades obreras y formaron el Comité Sindical de Ayuda al Proletariado Español, en el cual se integraron los gremios bajo su tutela junto con los de la corriente sindicalista agrupados en la reconstruida Unión Sindical Argentina (USA). De esta forma, a mediados de 1937 la FACA pasó a formar parte de un organismo más amplio, la Comisión Coordinadora de Ayuda a España en la Argentina (CCAEA), integrada por varios gremios autónomos y los pertenecientes a la USA, el Partido Socialista Obrero, junto con el aporte de reducidos núcleos trotskistas y la participación inicial de los socialistas, que luego se retiraron, dejando la Coordinadora en manos de anarquistas y sindicalistas. ${ }^{1}$

La FACA también impulsó la creación de la filial local de la SIA (Solidaridad Internacional Antifascista), organización fundada por los anarquistas españoles en 1937 tras no conseguir el respaldo esperado de parte de la AIT (Asociación Internacional de Trabajadores). ${ }^{2}$ La SIA se erigió con objetivos ambiciosos a escala internacional, y aunque en Argentina no alcanzó el mismo desarrollo que en otras naciones, logró crear seccionales en varios puntos del país y desarrollar una labor propagandística importante. La convocatoria impulsada por esta entidad era aglomerar al activismo antifascista más allá de su adhesión política-ideológica en particular, en lo cual también tuvo relativo éxito. Por su parte la FACA buscó aprovechar la situación de ser la fundadora de esta entidad internacional en el país para mantenerla bajo su dirección, pero ante la participación de experimentados militantes de otras organizaciones en su seno, sumado a que el grueso de las recaudaciones materiales continuaron proviniendo de la CCAEA, debieron relegar esa pretensión (López Trujillo, 2005, pp. 174-187).

Por su parte, los periódicos La Protesta, Dos Fraie Vort (Libre Pala-

1. Comisión Coordinadora de Ayuda a España en la Argentina, Memoria y Balance. Correspondientes a los últimos ejercicios, Buenos Aires, julio de 1938.

2. El desencuentro entre la CNT y la entidad internacional se originó porque la organización española no estaba de acuerdo con que el Fondo de Socorro Internacional, órgano solidario de la AIT, reparta el $80 \%$ de los aportes recibidos de sus secciones a la CNT y que el $20 \%$ restante se destine a otros países con problemas represivos, como Alemania. Ante el desacuerdo de este criterio la CNT crea la SIA para evitar, y remplazar, la orgánica de la AIT. 
bra) y La Obra (dirigido por Rodolfo González Pacheco) conformaron el Comité Anarquista de Defensa y Ayuda a la CNT y FAI. Organismo que editó un boletín a base de informes y comunicados producidos por las organizaciones libertarias españolas ${ }^{3}$ y que coordinó dos envíos de provisiones en colaboración con la FACA, el Comité de Ayuda a la Causa del Pueblo Español (La Plata) y el Comité Sindical, valuados por un total de $\$ 44.223,14$. El motivo por el cual este grupo de periódicos anarquistas decidieron trabajar de forma independiente al CCAEA se debe a su desacuerdo en torno a integrar alianzas amplias con agrupaciones de otras tendencias políticas. ${ }^{4}$

La FORA prefirió encauzar la ayuda a través de su propia orgánica, rechazando integrar los comités surgidos en la ocasión por dos motivos: primero, su aversión hacia las organizaciones políticas y su desconfianza hacia los fines perseguidos por aquellas entidades que formulaban constantemente la necesidad de una coordinación. Por ejemplo, ante la creación de la CCAEA la FORA publicó una nota en donde señalaba los intereses contrapuestos perseguidos por quienes la constituían, dado que su heterogeneidad no dejaba en claro sus objetivos: "¿A qué España pretenden salvar? Es muy dificil poder precisarlo. Como no deja de ser un rompecabezas a donde irá a parar el dinero que recolecten: ¿al gobierno, a la UGT, a los bolcheviques de Stalin o de Troztky [sic], a los partidarios republicanos?". ${ }^{5} \mathrm{El}$ otro motivo esgrimido era que su organización ya contaba con una entidad dentro de su estructura que se dedicaba exclusivamente al socorro solidario, el Comité Pro Presos y Deportados (CPPyD). Este organismo tenía la función de asistir y acompañar a los militantes detenidos o deportados y a sus familiares, por ello la FORA sostuvo que este Comité contaba con la capacidad de encauzar las colectas y las actividades solidarias destinadas a España dada su experiencia.

Si bien señalamos que la política adoptada por la FORA a nivel nacional era brindar su apoyo de forma independiente, la autonomía que regía al interior de esta federación habilitó que algunos de sus gremios terminen sumándose a la coordinación local con entidades de diferentes

3. Este Comité publicó varias circulares y un Boletín Informativo de 8 ejemplares, editado entre el 30 de julio de 1937 y el 15 de enero de 1938, más un Boletín Extraordinario de mayo de ese año, en los cuales compilaban y difundían información de las organizaciones anarquistas de España.

4. Luego del alejamiento de los periódicos anarquistas, la CCAEA realizó dos envíos de viveres durante 1937 por un valor de $\$ 73.325$, contando con el significativo aporte del Partido Socialista antes de que se desvincule de la Coordinadora (López Trujillo, 2005, p. 174).

5. "Lo que se gesta al calor de los acontecimientos españoles", en Organización Obrera, $n^{\circ} 38$, abril de 1937 , p. 2. 
tintes políticos (Quijada, 1991, p. 142). De forma inversa, varias agrupaciones obreras que no pertenecieron orgánicamente a la FORA prestaron su colaboración solidaria remitiendo las contribuciones recaudadas a esa organización, tal como la Unión Obreros Tranviarios, Sombrereros Unidos, varias seccionales de la Federación Obrera Ferroviaria o diversos sindicatos de Oficios Varios desperdigados por las áreas rurales del país (Salto, Charata, San Cristóbal -Buenos Aires-, Sáenz Peña-Chaco-, San Juan, etc.). ${ }^{6}$

A partir de lo expuesto se vislumbra que al interior del ámbito anarquista existieron diferentes estrategias organizativas en torno a las campañas a favor del pueblo español, divergencia que también se manifestó en torno al tipo de útiles a remitir y sus destinatarios. De parte de los CAPE y la CCAEA primó el criterio de enviar viveres y ropa, en tanto que la FORA decidió girar directamente dinero. El beneficiario de lo colectado por la FORA era exclusivamente su par anarcosindicalista, la Confederación Nacional del Trabajo (CNT), mientras que la CCAEA incluyó como receptor a la Unión General de Trabajadores (UGT) -central sindical de corte socialista-, de forma de beneficiar a todo el proletariado español con su colaboración.

Los aportes se juntaron a partir de la contribución voluntaria de los sindicatos afiliados, la venta de rifas y la confección de bonos por parte del Consejo Federal, los cuales fueron suministrados a los distintos gremios en forma de "listas" a fin de contar con una recaudación más regular. El dinero recolectado era girado sin ningún descuento previo al secretariado de la AIT radicado en París, recaudo adoptado para asegurar su efectiva entrega a la CNT y evitar que termine en manos enemigas. ${ }^{7}$ De acuerdo a los balances publicados en Organización Obrera los giros efectuados por la FORA fueron de un total de 272.296,20 francos, es decir: $36.819,85$ pesos argentinos. ${ }^{8}$

A su vez, cada gremio encaró diferentes actividades con miras a

6. Balance desde el $1^{\circ}$ de septiembre de 1936 a octubre 30 de 1939, Comité Pro-Presos y Deportados de la Capital, Buenos Aires, 1940; Organización Obrera, ${ }^{\circ} 33$, octubre de 1936 , p. 1 ; $n^{\circ} 34$, noviembre de 1936 , p. 1 ; no 47 , marzo de 1938 , p. 3 , $n^{\circ} 49$, junio de 1938, p. 6.

7. El Comité de Relaciones de Mineros de Asturias de la CNT y UGT circuló un manifiesto donde solicitaba que la ayuda recaudada para los trabajadores españoles no sea remitida por medio de la embajada española, dado que la misma terminaba en manos de los fascistas. Por ello señalaban que la forma de realizarlo fuera por intermedio de la AIT a través de sus Comités de Defensa de la Revolución Española. En “iCuidado!”, La Voz del Chauffeur, Sociedad de Resistencia Unión Chauffeurs, año $5, n^{\circ} 13$, septiembre de 1937, p. 5 .

8. Balance extraído de los ejemplares de Organización Obrera, $\mathrm{n}^{\circ}$ 39, mayo de $1937 \mathrm{p}$. $21 ; n^{\circ} 49$, junio de 1938 , p. $2 ; n^{\circ} 50$, agosto de 1938 , p. $3 ; n^{\circ} 54$, febrero de 1939 , p. 7. 
ampliar aquellos aportes económicos, como festivales de teatro, recitados de poesía, o los pic nics organizados junto al Comité Pro Presos y Deportados en las playas de Bernal, Isla Maciel o Tigre. Además de recaudar fondos para mandar a España, estas actividades tuvieron como objetivo informar a los concurrentes de las últimas novedades de la guerra y fomentar un ámbito de sociabilidad libertaria e internacionalista, posibilitando a los organizadores trascender su propio núcleo de afiliados e interesar a un público más amplio sobre sus postulados.

Otra faceta de la guerra de España que involucró enérgicamente a los anarquistas fue la tarea de difundir las novedades recibidas. Si bien esta actividad no fue obra exclusiva de ninguna corriente de pensamiento, la impronta otorgada por parte de los libertarios fue particular al resaltar la gesta revolucionaria desarrollada en los primeros meses de guerra con la puesta en práctica de colectivizaciones agrícolas y la producción autogestionaria de fábricas y servicios urbanos (Mintz, 2008; Gavaldá, 2019), proceso que se convertirá en un hito histórico para el movimiento anarquista internacional. La información circulante incluía noticias de los sucesos ocurridos a lo largo de la guerra, reproducciones de manifiestos o comunicados de las organizaciones libertarias de España, perfiles personales de combatientes destacados como Durruti y reflexiones políticas sobre las implicancias de los acontecimientos ibéricos, tanto para su propio pueblo como para el resto del mundo.

Los medios utilizados para esta difusión fueron las publicaciones gráficas y las reuniones o actos públicos, donde algunos oradores de referencia exponían su punto de vista respecto a lo acontecido. Toda la prensa libertaria de la época, junto con los periódicos sindicales vinculados al movimiento, le otorgaron un lugar primordial a los artículos sobre la guerra y la revolución en España, permitiéndose polemizar en base a las impresiones de la obra realizada. Particular importancia de difusión tuvo la publicación confeccionada por la FACA denominada Documentos Históricos de España, tarea facilitada por el puesto que ocupó Jacobo Prince en la Sección Sudamericana del Servicio de Propaganda de la CNT-FAI. También por medio del formato libro se buscó contribuir a esta tarea, pero ya no solo para informar sino para asentar un posicionamiento político-ideológico sobre el proceso en marcha. Algunos de los títulos más influyentes en esta empresa fueron La revolución y la guerra en España, de Abad de Santillán (1938), y Las pendientes resbaladizas, de Azaretto (1939). Una vez concluida la guerra se editaron cientos de libros sobre la temática, dedicándose a analizar la contienda desde una situación más serena y provistos de mayor documentación. ${ }^{9}$

9. Como caso emblemático, el libro recién citado de Santillán, le sirvió al autor de 


\section{Poniendo el cuerpo por la emancipación}

Ante el inicio de la guerra y los auspicios de la lucha revolucionaria emprendida por los anarquistas en España, sus pares locales se vieron interpelados, deseosos de brindar su colaboración y ser parte de esa gesta. A las acciones solidarias ya señaladas se sumó el embarque de varios militantes, que a pesar de estar informados que lo más necesario eran armas y viveres, igualmente se dispusieron a viajar para involucrarse de forma directa en la contienda. Impulso, aunque de forma más organizada, compartido por los comunistas, no así por los socialistas y sindicalistas. Las ansias de los ácratas por contribuir con esta empresa se relacionan con el hecho de que "era España (y especialmente Aragón y Cataluña) el lugar donde el anarquismo tenía sus mayores fuerzas. Y hacia allí marchan cientos de libertarios desde la Argentina, para enrolarse en las columnas de la CNT y la FAI" (Trifone y Svarzman, 1993, p. 79).

En la presente pesquisa se han registrado un total de 98 anarquistas que efectivamente participaron de la guerra, sumando la identificación de 25 individuos a los 73 ya señalados en estudios precedentes (González, Boragina, Sommaro y Dorado, 2008, pp. 173-201; Baumann, 2009, pp. 41-53; Migueláñez Martínez, 2018, pp. 231-246). Si bien la expresión de que "cientos" de anarquistas viajaron a España resulta exagerada, las experiencias de quienes arribaron a la península nos dan la pauta de las dificultades presentes para tener un registro acabado sobre los mismos. Uno de los primeros problemas que surge para dar con esta información es poder identificar la identidad política de muchos ácratas, quienes por precaución buscaron ocultar su filiación ideológica. Otro factor que agravó esta tarea fue la modalidad semi clandestina de embarcarse que debieron adoptar los voluntarios una vez que los puertos de España fueron cerrados ante el inicio de la guerra-viéndose obligados a descender en zonas próximas a aquel país y proseguir por otros medios de transporte-. A su vez, la mayoria de estos individuos viajaron de forma anónima, sin auspicio o apoyo explícito de alguna organización, y en muchos casos con identificaciones falsas (Campione, 2018, pp. 233-234). Por último, es de destacar que la precaria organización administrativa y el carácter anti personalista del anarquismo, por su oposición a la figura de líderes y jefes, colaboraron en la falta de registros de quiénes y cuántos de sus integrantes terminaron formando parte de la guerra.

El nombre de algunos anarquistas de Argentina que participaron en

base para "refundirlo" en su obra aún más conocida, ¿Por qué perdimos la guerra?, editado en 1940 en Buenos Aires. 
la GCE se advierte rápidamente, dada la fama que les precedía por su desenvolvimiento en América, tales como el dramaturgo Rodolfo González Pacheco, el intelectual Diego Abad de Santillán o el ajusticiador Simón Radowitzky. ${ }^{10}$ Para el resto, su identificación está ligada a la inserción que lograron durante la guerra, la cual varió entre quienes se integraron a las tareas administrativas dentro de las organizaciones libertarias españolas, aquellos que se dedicaron a actividades artísticas y quienes se entregaron al combate en el frente. La experiencia compartida por todos ellos se basó en la certeza de estar viviendo un momento único al enfrentar de forma directa la avanzada del fascismo, junto a la esperanza -más breve en unos que en otros- de lograr una salida revolucionaria.

Quienes alcanzaron mayor notoriedad en España fueron quienes viajaron en calidad de delegados de sus organizaciones locales para ejercer una representación directa. De esta forma, por parte de la AOS fue designado Horacio Badaraco y por la FACA Jacobo Prince, Jacobo Maguid (Jacinto Cimazo) y José Grunfeld. Todos estos activistas dejaron abundante registros de su experiencia durante la guerra, a través de documentos orgánicos, memorias y/o trabajos biográficos (Maguid, 1984, pp. 21-27; Maguid, 1995, pp. 41-53; Grunfeld, 2000, pp. 176216; Rosales, 2001, pp. 327-333). La representación de La Protesta la ejercieron indirectamente dos de sus ex integrantes, José Verde y Manuel Villar, deportados en $1933 .{ }^{11}$ Otros que cobraron relevancia fueron quienes ocuparon puestos de responsabilidad en la retaguardia, como Ana Piacenza -única mujer de la que tenemos registro-, quien trabajó en el periódico Tierra y Libertad de la FAI y en la organización "Mujeres Libres" (Bordagaray, 2013); Laureano Riera Díaz, representante de la FAI Catalana en el Comité de Enlace de las Secciones de Defensa CNT-FAI; José María Lunazzi, representante de la FAI en el Consejo de Economía de Cataluña; Antonio Casanova, secretario de la Sección de Defensa -todos ellos pertenecientes a la FACA, pero no mandatados como delegados de la misma-, y Manuel Villar, en el Comité Central de Abastos de Cataluña en nombre de la FAI, y luego director de Fragua Social de la CNT de Valencia (Wessels, 2005, pp. 22-26).

10. Al ser considerado un simbolo del movimiento anarquista a nivel internacional, los españoles tomaron la decisión de no exponer a Radowitzky a mayores riesgos, prohibiéndole que vaya a pelear al frente. Fue designado a tareas de enlace, pero su descontento por no compartir la suerte de sus compañeros lo llevó a desobedecer su mandato y a participar de la batalla de Teruel, donde casi deja la vida. Luego de pasar una temporada en el hospital, y llegado el momento de la impostergable retirada, le confieren la importante misión de salvaguardar el archivo histórico de la CNT-FAI, el mismo que hoy día se halla alojado en el Instituto Internacional de Historia Social de Ámsterdam (Martí, 2010, pp. 291-302).

11. "El Congreso Anarquista", La Protesta, mayo de 1937, p. 2. 
De aquellos que asistieron al frente de batalla se conoce menos aun. En esta dificil tarea de rastrear trayectorias personales Jerónimo Boragina pudo identificar a diez anarquistas argentinos que, sin ser conocidos por su militancia previa, se incorporaron a la contienda y accedieron a cargos de jerarquía, como el caso de Jorge Testena -comandante- y Argentino Eizaguirre -teniente- (Boragina, 2015, p. 191). Todavía más difícil es encontrar registros de aquellos militantes que oficiaron meramente como combatientes. De este perfil da cuenta la muerte del ladrillero forista Fausto Falasqui, caído en la batalla de Monte Pelado en agosto de 1936, ${ }^{12}$ y de los choferes José Calvillo y José "Saluto" López -quien fuese secretario de aquel sindicato- en $1937 .{ }^{13} \mathrm{Sin}$ caer en el fatal destino de estos, pero participando de igual forma en el frente, hallamos a otros dos choferes de la FORA: Jerónimo Rodríguez y Losoya, quien, según un viejo militante anarquista, era "un pacifista, entonces se dedicó a manejar una ambulancia en la guerra civil, no quería ni matar ni ser muerto". ${ }^{14}$

La dispersión de la información acerca de la participación de los militantes de la FORA en gran medida se debe a la decisión asumida por la propia federación de no enviar delegados directos a España, además de los factores ya referidos. La determinación de su Consejo Federal fue justificada ante la Reunión Regional de Delegados de 1938, fundamentando que la organización no contaba con los medios económicos necesarios para afrontar dicho gastos. ${ }^{15}$ Ante la discusión que suscitó este tema, algunos sindicatos demostraron su desacuerdo con dicha posición, manifestando que de conjunto esa situación podría haber sido sorteada. De hecho, la Unión Chauffeurs informó que su gremio facilitó el viaje de varios de sus militantes a España para que se sumen a los escuadrones confederales, pero sin dar más detalles al respecto que los señalados en su prensa. En contraposición con los delegados enviados por la FACA, los miembros de la FORA presentes en España no contaron con un mandato que les permitiese representar a la Federación de forma orgánica. A excepción de Montero, ${ }^{16}$ los dieciséis foristas que

12. Organización Obrera, año II, $\mathrm{n}^{\circ} 32$, octubre de 1936, p. 2; "Defendiendo la anarquía cayó Falasqui”, La Protesta, octubre 1936, p. 1.

13. "Recordando a dos compañeros" en La Voz del Chauffeur, Sociedad de Resistencia Unión Chauffeurs, año 6, $\mathrm{n}^{\circ} 12$, junio de 1937, p. 1

14. Carlos Kar (alias Puchero). Entrevista realizada por Nicolás Iñigo Carrera el 8 de octubre de 2016 en la ciudad de Buenos Aires.

15. FORA, Actas y Acuerdos de la Reunión Regional de Delegados de la FORA, marzo de 1938, Buenos Aires, p. 25.

16. José María Montero era de origen gallego, se bautizó en las luchas proletarias de Argentina con la huelga a la General Motors de 1928. En 1930 fue condenado 
intervinieron en la contienda española ${ }^{17}$ no dejaron memorias escritas, ni información precisa sobre el rol que desempeñaron; los registros sobre la participación de los mismos son incorporados a partir de algunos testimonios laterales como el de Laureano Riera Díaz, ${ }^{18}$ o por el contenido de notas reproducidas en la prensa obrera de la época que informan de la desesperada situación de algunos militantes en territorio español. ${ }^{19}$

Dentro de los voluntarios registrados se incluye a varias personas que no nacieron en Argentina pero que tuvieron una residencia duradera en nuestro país y se incorporaron de lleno al activismo anarquista local, españoles los más (28), pero también italianos (5), franceses (1) y rusos (1). También se computan como voluntarios a quienes ya se encontraban en España de forma previa a la sublevación militar (19), los cuales debieron abandonar la Argentina de forma forzada a causa de las deportaciones (14), por la persecución política (3), tales como Abad de Santillán, Villar y Leval, o aquellos argentinos que simplemente se encontraban trabajando y militando en la CNT antes del golpe (2), como el periodista Valentín de Pedro (Calero, 2018, pp. 79-113) y el pedagogo Edgardo Ricetti (Copparoni, 1992, pp. 24-37). La rápida adaptación de estos militantes a diferentes realidades socioculturales da cuenta del carácter trasnacional asumido por el anarquismo, permitiendo la conexión de sus integrantes más allá de su lugar de origen (Baer, 2015, p. 110). De hecho, las redes entabladas entre libertarios de diferentes latitudes de forma previa a la guerra ayudaron a la comunicación e integración de los voluntarios extranjeros al convulsionado ambiente español. Abad de Santillán, ya asentado en el movimiento ibérico, cumplió un

a muerte por la dictadura de Uriburu junto a otros dos choferes de la FORA y tras conseguir el indulto es trasladado al presidio de Ushuaia. Luego de ser puesto en libertad durante la presidencia de Justo, es deportado. Finalmente, tras vivir de forma clandestina durante dos años, acordó con otros dos compañeros embarcarse hacia España, viajando de polizón junto a Laureano Riera Díaz y otro español llamado Diego. Una vez allí llegó a ser designado teniente en el Cuerpo del Ejército $n^{\circ} 10$, al mando de un equipo del Servicio de Investigación Militar (Ortiz, 1974, pp. 104-120).

17. A los ya mencionados se agregarian: Abelino Fernández, Benigno Mancedo (jornalero deportado en noviembre de 1930), Ildefonso González Gil, Bartolomé Lorda (ambos deportados en 1931), Ismael Martí (pintor deportado en abril de 1933), Real, Vázquez y López (choferes deportados a fines de 1936), Serafin Fernández (ladrillero deportado en abril de 1937), Jorge Rey Villalba (pintor deportado en 1937).

18. Al relatar su encuentro con Simón Radowitzky en la Casa de la CNT-FAI de Barcelona, el autor comenta que este convivia con un grupo de choferes de la FORA, "deportados por la dictadura de Uriburu algunos y otros que fueron a España por voluntad propia” (Riera Diaz, 1981, p. 379).

19. "Correspondencia", La Voz del Chauffeur, año 6, n 13, septiembre de 1937, p. 2; "Los Refugiados", La Voz del Chauffeur, año 8, n 17, mayo de 1939, p. 7. 
rol fundamental en la tarea de aconsejar y relacionar a las diferentes agrupaciones, destacando a muchos de los inmigrados a tareas en la retaguardia (Migueláñez Martínez, 2018, pp. 232-236).

En base a la información recabada se pudo identificar a casi un centenar de individuos que participaron de la guerra de diferentes maneras, siendo más sencillo el registro de quienes fueron militares destacados o cumplieron funciones administrativas (21) por sobre aquellos que se desempeñaron en el frente de batalla (48). Es el acceso a la figura de algunos de estos "desconocidos" lo que nos permite pensar en la posibilidad de que hayan sido varios más los libertarios involucrados en la contienda de forma anónima.

\section{La guerra de apreciaciones}

Con el trascurrir de la guerra el movimiento anarquista internacional se encontró involucrado en los debates entablados al interior de España. Dada la magnitud de la experiencia autogestiva desarrollada en aquella región, los demás ácratas del globo se sintieron interpelados por el devenir de aquel proceso, siguiendo de cerca las respuestas políticas ensayadas por las organizaciones representativas del anarquismo ibérico, derivando en profundos debates en torno a, principalmente, dos puntos: la integración política de los libertarios con las demás fuerzas del bando republicano y la participación de delegados de la CNT y FAI en cargos gubernamentales.

Las primeras noticias publicadas sobre España fueron del todo elogiosas hacia las organizaciones del anarquismo ibérico y las masas obreras que tomaron las armas para evitar la conquista del poder por parte de los facciosos. ${ }^{20}$ Cuando en el mes de septiembre se difundieron los acuerdos de acción conjunta entablados entre la CNT y la UGT en varias localidades de España, los periódicos libertarios locales aclararon que la pretensión de sus camaradas ibéricos no era realizar un "frente popular" de acuerdo al modelo planteado por los comunistas, ya que esa política era denunciada por los anarquistas por tratarse de una "unidad" que, bajo la excusa de combatir a un enemigo común, buscaba la capitalización del esfuerzo colectivo en beneficio de estructuras partidarias. En contraposición, el planteo desarrollado de estos era el de establecer una "unidad de acción", es decir, trabajar en conjunto

20. "La CNT y FAI impidieron triunfase el fascismo", "La causa del pueblo fue bautizada con sangre anarquista", "La Federación Obrera Local Bonaerense envía su fraternal saludo", en La Protesta, no 7848, 15 de agosto de 1936, p. 1. 
con los demás sectores que compartían sus objetivos, sin efectuar un compromiso político a futuro. ${ }^{21}$

En octubre, entre los grandes títulos que celebraban la actuación de los anarquistas ibéricos, La Protesta publicó un pequeño recuadro titulado "La CNT frente al gobierno de Caballero", en el cual presentaban los puntos que aquella organización delineó para poder desarrollar una acción en conjunto con los republicanos, a saber: " $1^{\circ}$. Apoyo decidido del nuevo gobierno para que éste cumpla su misión esencial, que es la de aplastar la insurrección fascista. $2^{\circ}$. Creación en cada ministerio de una comisión o consejo asesor, integrado por representantes de la CNT, de la UGT y del Frente Popular y de un delegado del gobierno". ${ }^{22}$ Estos representaron un cambio histórico en la relación entablada por los anarquistas con el Estado, la cual se profundizó a partir del 4 de noviembre cuando cuatro de los más notables militantes libertarios pasaron a integrar al gobierno de la República. Decisión política que derivó en agrias discusiones para los anarquistas, dentro y fuera de las fronteras de la península.

Hasta mediados de 1937 la discusión al interior del movimiento anarquista argentino se centró en la organización de la campaña solidaria. La FORA y La Protesta, entidades tradicionalmente asociadas, entraron en acusaciones mutuas respecto al rol desempeñado en la recolección de bienes para girar a España. Pero en poco tiempo esta discusión pasó a un segundo plano cuando cobró notoriedad el hecho, ya mencionado, de la intervención de algunos anarquistas en el gobierno. La disyuntiva planteada versaba sobre si era posible la excepcionalidad en torno a uno de los principios más elementales del anarquismo, en razón de las particulares circunstancias del momento, o si simplemente significaba una claudicación a sus ideales y por ende una traición. Acaso, ¿era un error o una acción premeditada?

Al menos hasta los primeros meses de 1937, la FORA mantuvo una postura cautelosa ante estas noticias llegadas de España. El cambio de mirada va a quedar reflejado en su órgano de prensa a través de artículos como los de Bernardo Díaz, militante de origen español residente en Tucumán, quien en un principio justificó lo actuado por la CNT al considerar que la presencia de los anarquistas en las tomas de decisiones era la única garantía de que la revolución no sea cooptada por una burocracia que desvirtúe su proyección (en comparación con el caso

21. "El Frente Único en la acción”, en La Protesta, n 7849, septiembre de 1936, p. 2; "En vez de frente político, sólida unidad proletaria", en Acción Libertaria, año 11, $\mathrm{n}^{\circ} 21,6$ de octubre de 1936, p. 1

22. "La CNT frente al gobierno de Caballero", La Protesta, n 7850, octubre de 1936, p. 3 
ruso). ${ }^{23}$ Pero tan solo un mes después el mismo autor publicó una nota titulada “¿Sera permitido hablar?", en la cual criticó el silencio cómplice y hasta el intento de censura, por parte de otros compañeros de ideas, al señalarse aspectos contradictorios del proceder de los colegas ibéricos, puntualizando en la desviación de acuerdos adoptados a nivel nacional, robusteciendo así el principio de autoridad que dicen combatir. ${ }^{24}$

De esta forma, desde mediados de 1937 la división de criterios dentro del ámbito anarquista local resultó tajante. La Protesta intentó convencer a la FORA de que retome una posición menos crítica hacia los militantes de España, señalando que sería más fructífero que reencauce sus esfuerzos en la campaña solidaria antes de dedicarse a exponer los errores "tácticos" ocurridos al fragor de la guerra. ${ }^{25}$ En este sentido, La Protesta conservó una posición intermedia que osciló entre el resquemor por las posiciones asumidas por los libertarios de España y el apoyo al pueblo en armas. En cambio los periódicos La Obra y La Batalla asumieron posiciones más duras en contra de la política integracionista. En el plano opuesto, la FACA fue la organización que más firmemente defendió lo realizado por las organizaciones anarquistas ibéricas, entendiendo que las opciones que se les presentaron ante el alzamiento militar fueron, o hacer valer su peso numérico para llevar adelante sus postulados revolucionarios ante el vacío de poder, imponiendo un control dictatorial sobre los demás sectores sociales, o coordinar con las diferentes fuerzas antifascistas los pasos a seguir en la guerra para evitar el triunfo de los sublevados. ${ }^{26}$

Algunos militantes de la FORA intentaron esclarecer la cuestión, plantearon la necesidad de discutir abiertamente los problemas que afectaban al conjunto del anarquismo, dado que "la sola suposición de que ha de silenciarse toda crítica implica de por sí sólo un grave riesgo para el movimiento" ${ }^{27}$ En este sentido, los foristas apuntaron a ejercer un juicio sereno y "objetivo", sin dejarse guiar por la simpatía o

23. "Carácter anárquico de la revolución española", en Organización Obrera, año V, n 39 , mayo de 1937, pp. 17-19.

24. “¿Sera permitido hablar?”, en Organización Obrera, año V, n 40, junio de 1937, p. 2.

25. Edmundo Latelaro, "Es imprescindible que la FORA encare la defensa de la revolución social española como cuadra a sus objetivos revolucionarios", La Protesta, año XL, $\mathrm{n}^{\circ} 7858$, julio de 1937, p. 4; "La reacción obliga a los militantes de la FORA a una solidaridad más efectiva con la CNT y FAI", La Protesta, año XLI, n 7864 , enero de 1938, p. 2.

26. "Experiencia de la colaboración antifascista en España", en Acción Libertaria, ${ }^{\circ}$ 47, agosto de 1941, p. 2.

27. "El fantasma de los cismas", en Organización Obrera, año VI, n 47, marzo de 1938, p. 2. 
el carácter heroico de lo realizado por el pueblo español. Señalaron que muy pocas publicaciones ácratas se atrevian a cuestionar las políticas adoptadas por la CNT-FAI, por primar el criterio de no ejercer críticas hacia lo realizado en España, ya que significaría estar haciéndole la guerra a sus propios compañeros. ${ }^{28}$ Este debate se plasmó al interior de la FORA en la Reunión Regional de Delegados de 1938, en la cual se adoptó la siguiente resolución:

Declaración sobre el problema español:

Considerando que independientemente de las alternativas de la lucha que nuestros camaradas sostienen en España con un fin manumisor y de las críticas que merecen por la colaboración con el Estado y los pactos con otras tendencias autoritarias, que no sea óbice (sin dejar de criticar lo criticable) para persistir en ayudar a nuestros compañeros de la CNT y el pueblo que los acompaña en la lucha, hasta que ella termine, teniendo en cuenta los acuerdos del último Congreso de la AIT referente a España, y que tenga relación con lo propuesto en esta moción. ${ }^{29}$

La FORA señaló de forma persistente las "desviaciones y contradicciones" ejercidas por la CNT-FAI, remarcando que, en parte, la causa de la derrota popular se hallaba en la traición efectuada por sus propios líderes. ${ }^{30}$ Por el contrario, la FACA argumentó que la pérdida de influencia de los anarquistas en la guerra, y su posterior derrota, se debian únicamente a causas exógenas, tales como la centralización militar en manos de los comunistas, la tibieza de los republicanos, el no apoyo de los países democráticos, etc. ${ }^{31}$ La autocrítica por parte del mismo movimiento libertario español sobre la participación gubernamental se convertirá, a lo largo del exilio, en un debate recurrente. Tema que se hizo extensivo entre los anarquistas de todo el globo, incluyendo a la Argentina.

28. José Barrionuevo, "A propósito del derecho y la necesidad de la crítica", en Organización Obrera, año VI, nº 47, marzo de 1938, p. 3.

29. FORA, Estructura orgánica, acuerdos y resoluciones de sus congresos y reuniones regionales, Buenos Aires, Ediciones FORA, 2014, p. 52.

30. "El ejemplo de España”, en Organización Obrera, n 55, marzo de 1939, p. 1.

31. El informe que los delegados de la FACA presentaron ante el Congreso de su organización en 1940 fue reproducido a través de su prensa en varios artículos: "Del Informe de Nuestros Delegados en España", en Acción Libertaria, n 46-48, 50-51 y 55. También transcripto en la obra de Jacobo Maguid (1994, pp. 44-114). 


\section{Conclusiones}

La GCE repercutió en la sociedad argentina como pocos fenómenos internacionales lo hicieron. Se colaboró con unos, se protestó contra otros, se polemizó con propios y ajenos, se organizaron actividades, se escribieron cartas y hubo hasta quienes se embarcaron para participar de forma directa. Representó una confrontación de ideas entre diferentes proposiciones politicas, religiosas y culturales; varios proyectos de nación dirimieron su destino a través de las armas al otro lado del Atlántico, replicándose de este lado por medio de la propaganda y las colectas que cada bando organizó.

Con la misma pasión con la cual difundieron las novedades llegadas de España y militaron la campaña solidaria, los anarquistas locales se sintieron con el derecho de cuestionar las politicas adoptadas por las organizaciones libertarias hispánicas, en particular la participación en el gobierno y la aceptación de conformar el Frente Popular. Este debate se extendió a escala global con tanta o más rapidez que las acciones solidarias, y en Argentina, como hemos visto, generaron fuertes discrepancias que ayudaron a profundizar las diferencias preexistentes. Entendemos que el antagonismo ilustrado en torno a este debate respondió a las interpretaciones realizadas sobre el contexto político y al compromiso táctico asumido con las organizaciones españolas. Como la mayoría de los militantes de la FACA ocuparon cargos administrativos dentro de la CNT y la FAI, se involucraron con la línea politica asumida por las mismas, defendiendo sus decisiones como fruto del contexto. En cambio la FORA, al igual que el resto de la AIT, asumió un rol crítico ante la política colaboracionista, advirtiendo sobre el peligro de reforzar las estructuras estatales y partidarias. Aun contemplando el dificil panorama que presentaba la guerra, esta tendencia apostó por una acción autónoma del proletariado para frenar al fascismo.

Las divergencias politicas entre los libertarios de Argentina también afectaron a la campaña solidaria. Si bien es sabido que el anarquismo nunca fue un movimiento homogéneo, bajo una dirección única y centralizada, por el contrario, reivindicó la autonomía de acción de grupos e individuos, en otras circunstancias históricas, como las campañas por la liberación de Radowitzky o las protestas por la condena de Sacco y Vanzetti, las diferencias de los distintos sectores pasaron a un segundo plano. Esto no sucedió ante la GCE, ya que las diferentes lecturas y tácticas asumidas derivaron en la falta más elemental de entendimiento, potenciando sus discrepancias e imposibilitando la articulación de una mayor ayuda hacia sus compañeros hispánicos. Si bien el debate organizativo que se puso de manifiesto durante la campaña giró en torno a si realizar alianzas con otras corrientes antifascistas o no, el planteo de 
fondo que estaba en disputa eran las nuevas propuestas organizativas y programáticas delineadas por la FACA y la AOS en torno al modelo de las agrupaciones anarquistas y las tácticas que deberian aplicarse en torno al activismo sindical para superar el estancamiento de la FORA (Ceruso, 2011, pp. 165-179). Es así que dos concepciones políticas se pusieron de manifiesto: quienes sostenían que los sindicatos deberian seguir siendo el centro privilegiado de la militancia (foristas), y aquellos que propugnaban por que los grupos anarquistas se conviertan en núcleos de debate ideológico, forjando posicionamientos políticas a implementar luego en los diferentes ámbitos de actuación (especifistas).

Para colaborar con la causa del pueblo español se estructuraron diferentes organizaciones de carácter solidario, producto de las relaciones de afinidad, colaboraciones y disidencias. Dentro del ámbito anarquista, los criterios de mayor inserción política y su espíritu renovador dotaron a la FACA y a la AOS de una mayor presencia en los comités populares creados para la ocasión, entablando la disputa con otras organizaciones para extender su influencia en su interior. La FORA conservó una postura autónoma, limitándose a recoger la solidaridad dentro los gremios adheridos y afines, así relegó una mayor proyección social al mismo tiempo que evitó confrontar con otras organizaciones sobre cómo proyectar su campaña. Estas diferencias también se vinculan con la propia conceptualización que cada organización tenía del antifascismo. Aun reconociendo el carácter autoritario del régimen soviético y el potencial peligro de su expansión internacional, la FACA y la AOS manifestaron una posición más receptiva respecto a la alianza con otras tendencias de izquierda por comprender que existía la urgencia de entablar un frente ante un enemigo común. En cambio la FORA sostuvo una postura más implacable, condenando tanto al fascismo "negro" como al "rojo", y por ende rechazando todo acuerdo con el PC por considerar que su estrategia de "Frente Popular" solo perseguía la subordinación de las otras fuerzas para su propio beneficio.

La naturaleza internacionalista del anarquismo le proporcionó una mirada amplia del mundo, no limitada por las fronteras nacionales, y una identidad solidaria que derivó en que lo sucedido en suelo español sea sentido como propio entre los libertarios de vastas regiones del mundo. Esta cosmovisión resultó en un fuerte compromiso por parte de los libertarios locales en esta empresa, incluso llevando al aplazamiento de muchas de sus tareas habituales, desatendiendo conflictos y campañas de carácter local. Durante casi tres años sus mayores esfuerzos e intereses se desplazaron de sus regiones de residencia hacia el otro lado del océano, donde el proyecto libertario pareció florecer brevemente. 


\section{Referencias}

Abad de Santillán, D. (1938). La revolución y la guerra en España. Notas preliminares para su historia. El Libro.

Abad de Santillán, D. (1940). Por qué perdimos la guerra. Una contribución a la historia de la tragedia española. Imán.

Anapios, L. (2013). La ley de jubilaciones de 1924 y la posición del anarquismo en argentina. Revista de Historia del Derecho, 46, 27-43.

Azaretto, M. (1939). Las pendientes resbaladizas (Los anarquistas en España). Germinal.

Baer, J. (2015). Anarchist immigrants in Spain and Argentina. University of Illinois Press.

Baumann, G.G. (2009). Los voluntarios latinoamericanos en la Guerra Civil Española. Ediciones de la Universidad de Castilla-La Mancha.

Benyo, J. (2005). La Alianza Obrera Spartacus. Libros de Anarres.

Boragina, J. (2015). "Voluntarios argentinos en las Brigadas Internacionales y en el movimiento anarquista español”. En J. Sánchez Cervelló y S. Agudo Blanco (coords.). Las Brigadas Internacionales: nuevas perspectivas en la historia de la Guerra Civil y del exilio (pp. 181-204). Universitat Rovira i Virgili.

Bordagaray, M. (2013). Luchas antifascistas y trayectorias generizadas en el movimiento libertario argentino (1936-1955). Cuadernos de H Ideas, 7, 7.

Calero, J.P. (2018). El argentino Valentín de Pedro en la España revolucionaria. Germinal. Revista de Estudios Libertarios, 14, 79-133.

Campione, D. (2018). La Guerra Civil Española, Argentina y los argentinos. Luxemburg.

Casas, S.L. (2007). La guerra civil española y el antifascismo en la Argentina (1936-1941). Los baleares y la ayuda a la República. Fundació Càtedra Iberoamericana.

Ceruso, D. (2011). El trabajo sindical de base del anarquismo argentino: la FACA y la Alianza Obrera Spartacus. A Contracorriente, 8, 3, 233-254.

Copparoni, E. (1992). Edgardo Ricetti. Maestro y luchador social. Reconstruir.

Gavaldá, A. (2019). Cataluña: avatares de la colectivización agraria (19361939). Fundación Anselmo Lorenzo-Universitat Rovira i Virgili.

González, L., Boragina, J., Sommaro E. y Dorado, G. (2008). Voluntarios de Argentina en la Guerra Civil Española. Centro Cultural de la Cooperación.

Grunfeld, J. (2000). Memorias de un anarquista. Grupo Editor Latinoamericano.

Jorge, D. (2014). El vector internacional aumenta en relevancia. Studia Historica. Historia Contemporánea, 32, 165-179.

López Trujillo, F. (2005). Vidas en rojo y negro. Una historia del anarquismo en la "década infame". Letra Libre.

Maguid, J. (1984). Una voz anarquista en la Argentina. Vida y pensamiento de Jacobo Prince. Reconstruir. 
Maguid, J. (1994). La Revolución Libertaria Española (1936-1939). Reconstruir.

Maguid, J. (1995). Recuerdos de un libertario. Setenta relatos de la militancia. Reconstruir.

Martí, A. (2010). La biografía del anarquista Simón Radowitzky. Del atentado a Falcón a la Guerra Civil Española. De La Campana.

Migueláñez Martínez, M. (2018). Más allá de las fronteras: el anarquismo argentino en el periodo de entreguerras. Tesis Doctoral, Universidad Autónoma de Madrid, Facultad de Filosofia y Letras.

Mintz, F. (2008). Autogestión y anarcosindicalismo en la España revolucionaria. Libros de Anarres.

Montenegro, S. (2002). La guerra civil española y la politica argentina. Tesis Doctoral, Universidad Complutense de Madrid, Facultad de Geografia e Historia.

Ortiz, M. (1974). El verbo prohibido. Memorias de un condenado a muerte. Talleres Gráficos Córdoba.

Quijada, M. (1991). Aires de República, aires de Cruzada: la Guerra Civil Española en la Argentina. Sendai.

Riera Díaz, L. (1981). Memorias de un luchador social 1926-1940. Tomo II. Edición del autor.

Rosales, J. (2001). Badaraco, el héroe prohibido. Anarquismo y luchas sociales en tiempos de infamia. La Rosa Blindada.

Trifone, V. y Svarzman, G. (1993). La repercusión de la guerra civil en la Argentina (1936-1939). CEAL.

Wessels, A. (2005). Militantes anarquistas del Río de la Plata en España. En P. Pérez (coord.). Catálogo de publicaciones, folletos y documentos anarquistas españoles. 1890-1939 (pp. 20-26). Reconstruir. 